\title{
Mortality from malaria in France, 2005 to 2014
}

Eric Kendjo ${ }^{1,2}$, Marc Thellier ${ }^{1,2}$, Harold Noël ${ }^{3}$, Stéphane Jauréguiberry ${ }^{2,4}$, Alexandra Septfons ${ }^{3}$, Oussama Mouri ${ }^{1,2}$, Frédérick Gay $^{1,2}$, Ilhame Tantaoui ${ }^{1,2}$, Eric Caumes ${ }^{4}$, Sandrine Houzé ${ }^{5,6}$, Renaud Piarroux ${ }^{1,2}$, on behalf of the French imported malaria Study group ${ }^{7}$

1. Sorbonne Université, INSERM, Institut Pierre-Louis d’Epidémiologie et de Santé Publique, AP-HP, Laboratoire de Parasitologie, Mycologie, Hôpital Pitié-Salpêtrière, Paris, France

2. AP-HP, Centre National de Référence du Paludisme, Paris, France

3. Santé Publique France, Direction des Maladies Infectieuses, Saint-Maurice, France

4. Sorbonne Université, INSERM, Institut Pierre-Louis d'Epidémiologie et de Santé Publique, AP-HP, Service des Maladies Infectieuses, Hôpital Pitié-Salpêtrière, Paris, France

5. Université de Paris, MERIT, IRD, Paris, France

6. Centre National de Référence du Paludisme, Hôpital Bichat, AP-HP, Paris, France

7. The members of the French imported malaria Study group are acknowledged at the end of this article

Correspondence: Eric Kendjo (eric.kendjo@gmail.com)

Citation style for this article:

Kendjo Eric, Thellier Marc, Noël Harold, Jauréguiberry Stéphane, Septfons Alexandra, Mouri Oussama, Gay Frédérick, Tantaoui Ilhame , Caumes Eric, Houzé Sandrine, Piarroux Renaud, on behalf of the French imported malaria Study group. Mortality from malaria in France, 2005 to 2014 . Euro Surveill. 2020;25(36):pii=1900579. https://doi.org/10.2807/1560-7917.ES.2020.25.36.1900579

Article submitted on 17 Sep 2019 / accepted on o9 Mar 2020 / published on 10 Sep 2020

Introduction: Malaria is a notifiable disease in all European Union and European Economic Area countries except Belgium and France, where only autochthonous malaria is notifiable. Although morbidity caused by malaria has been assessed, little is known about mortality incidence. Objective: Our aim was to estimate the number of imported malaria-related deaths in hospital in metropolitan France. Methods: We matched individual deaths reported between 1 January 2005 and 31 December 2014 to the French National Reference Centre for malaria (FNRCm) with malaria-related deaths from two other sources: the French National Registry on medical causes of death and the French national hospital discharge database. A capture-recapture method with log-linear modelling was used. Age, sex and place of death stratification were applied to remove heterogeneity. Results: The estimated malaria-related deaths in metropolitan France during the study period were 205 (95\% confidence interval (CI): 191-219). The annual mean number of malaria-related deaths was estimated at 21 (95\% $\mathrm{Cl}$ : 19-22). The FNRCm malaria-related deaths surveillance had a $38 \%$ sensitivity $(95 \% \mathrm{Cl}: 32-44)$. Among 161 in-hospital individual malaria-related deaths reported from three data sources, the sex ratio (male to female) was 2.6. Median age of the patients was 57 years, ranging from 1 to 89 years. Conclusion: The pertinent finding of this report is that malaria-related death records were significantly less* complete than case records. Therefore, data comparison of imported malaria morbidity and mortality between countries should imperatively be assessed using standard indicators weighted according to the completeness of health surveillance systems.

\section{Introduction}

In 2018, malaria ranked 16th among the leading causes of death [1], with an estimated 228 million cases and more than 405,000 deaths worldwide [2]. The World Health Organization European Region is the first in the world to have achieved interruption of autochthonous malaria transmission at the end of the 2oth century. However, malaria remains a threat for travellers to endemic areas. It is a notifiable disease in all European Union (EU) and European Economic Area (EEA) countries except Belgium and France, where only autochthonous malaria is notifiable. Based on data retrieved from The European Surveillance System (TESSy), 30 EU/EEA countries reported 8,393 confirmed malaria cases in 2017 [3]. France reported the highest number of cases $(n=2,712)$, followed by the United Kingdom (UK) $(n=1,777)$ and Germany $(n=956)$ [3]. Despite a diminution of cases and death in endemic areas, the 2017 figures for the EU/EEA were $27 \%$ higher than in 2013 ( $n=6,614$ ) [3]. Most cases of imported malaria in France and the UK are linked to travel to West Africa [4].

Among 4,874 confirmed malaria cases in the $30 \mathrm{EU} /$ EEA countries for whom the Plasmodium species was available, 3,989 (81.8\%) were infected with $P$. falciparum. The case fatality was $1.5 \%$ among 1,220 cases with $P$. falciparum malaria and a known outcome [3]. However, even in countries where malaria is a mandatorily reported disease, there is significant underreporting of cases and deaths. Thus, the completeness of the collection of cases was estimated at $21.2 \%$ for the period 2001 to 2011 in Portugal, 32.9\% for 2016 in Portugal (after changing the case reporting system), $40.2 \%$ in 1996 in the Netherlands and 56\% between July 2003 and December 2004 in the UK [5-8]. In addition, as has been shown in Portugal, the completeness 


\section{FIGURE 1}

Flowchart of malaria-related deaths from two sources, CépiDc and PMSI, metropolitan France, 2005-2014 $(\mathrm{n}=151)$

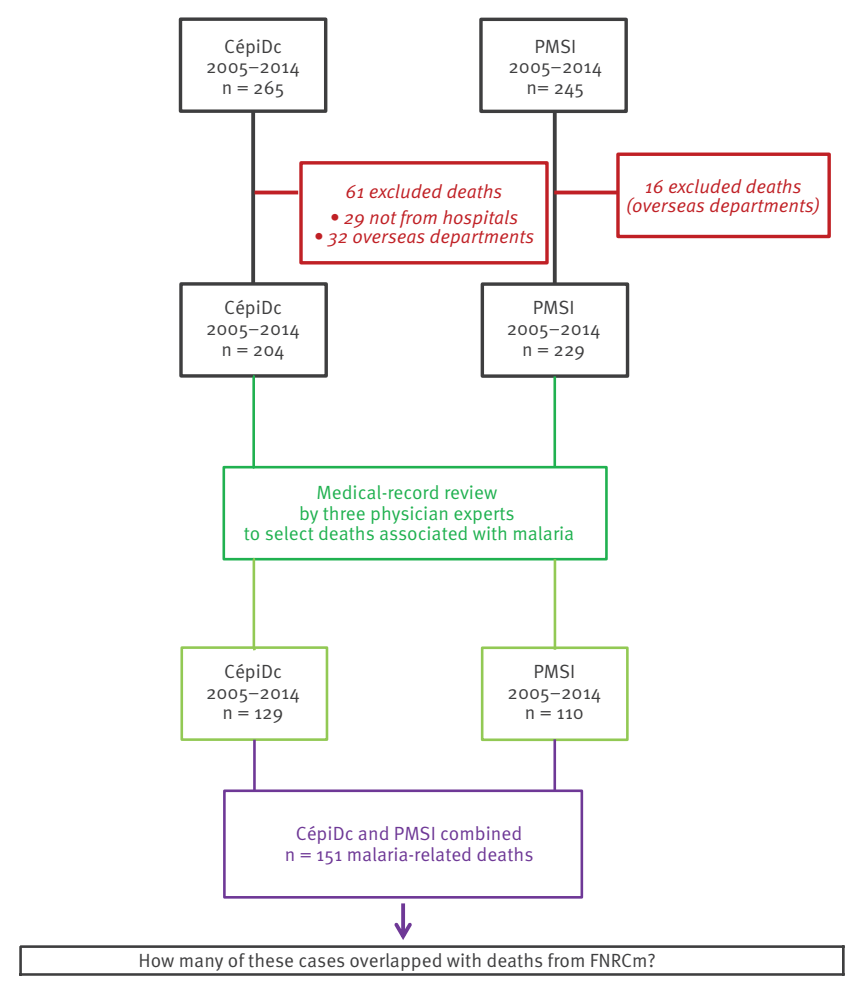

CépiDc: French National Registry on Medical Causes of Death; FNRCm: French National Reference Centre for Malaria; PMS French National Hospital Discharge Database (Programme de Médicalisation des Systèmes d'Information).

of the collection may be different for cases (21.2\%) and for deaths (26.5\%) [6].

In metropolitan France, using a homogenised definition for severe malaria cases, a recent study of the French National Reference Centre for Malaria (FNRCm) showed an increase in the proportion of severe malaria cases from $8.9 \%$ in 1996 to $16.7 \%$ in 2016 [9]. Surprisingly, over the same period, the number of deaths from malaria reported to $\mathrm{FNRCm}$ remained stable, ranging from five to 10 each year, with a case fatality rate of ca four per $1,000[9,10]$. The sensitivity of the FNRCm surveillance system for cases varied from $50 \%$ to $55 \%$ [11]. However, at present, the sensitivity of the FNRCm surveillance systems is unknown for individual deaths. Under-notification hides the real burden of malaria morbidity and mortality and negatively affects indicators for adequate malaria control. Therefore, the main objective of this study was to estimate the number of malaria-related deaths in hospitals in France.

\section{Methods}

\section{Study design}

A cross-sectional analysis was performed on mortality data using capture-recapture methods to estimate the number of individual deaths caused by all malaria species in metropolitan France from 2005 to 2014 [12]. The date period was chosen because modifications were made to the coding mode on the CépiDc database in 2000 and because accurate data for the period 2015 and 2016 were not available.

\section{Data sources}

Three data sources are available to capture malaria deaths in France: the French National Registry on Medical Causes of Death (CépiDc) [13], the French National Hospital Discharge Database (PMSI) [14], and the FNRCm [15]. These sources are fully digitalised and include individual-based data of malaria-related deaths in France. Data from these sources are used for public health monitoring.

\section{The French National Registry on Medical Causes of}

Death

The CépiDc has been managed by the French National Institute of Health and Medical Research (Inserm)'s public health programme since 1968 . The main objective of the CépiDc is the yearly production and analysis of national statistics of the medical causes of death in metropolitan France and overseas departments. This source helps authorities acquire a comprehensive understanding of the strengths and weaknesses of their mortality statistics systems. It also derives demographic and epidemiological measures that are needed in national planning in the health sector [13]. In France, death certification is mandatory and necessarily performed by a physician. The underlying cause of death is defined as the disease or injury that initiates the succession of morbid events leading to death [2]. The CépiDc contains one underlying cause of death (main cause) and more consecutive contributory causes of death (associated causes). Only some basic administrative information (date of birth, sex, place of birth, place of usual residence, date of death, place of death, and socio-professional category) is collected from death certificates. Since 2000, diagnoses reported to the CépiDc have been coded according to the International Classification of Diseases, 10th revision $($ ICD-10) $[16,17]$.

The French National Hospital Discharge Database The PMSI collects information on every hospital stay in France. Each hospital discharge report, corresponding to a hospital stay, is described according to the following items: reasons for hospitalisation (principal diagnosis) and related medical conditions (associated diagnoses) by ICD-10 code, length of hospital stay and characteristics of the patient (age, sex, place of hospitalisation and residence, health event/mortality) $[14,16]$.

The French National Reference Centre for Malaria The FNRCm is a sentinel network of ca 100 hospitals that fully reports malaria cases to a secured database and sends blood samples to reference laboratories based on voluntary participation. The mission of the 
Venn diagram over the distribution of individual deaths, showing overlap and unique cases for three data sources according to the experts' classification of cause of death, metropolitan France, 2005-2014 ( $\mathrm{n}=161)$

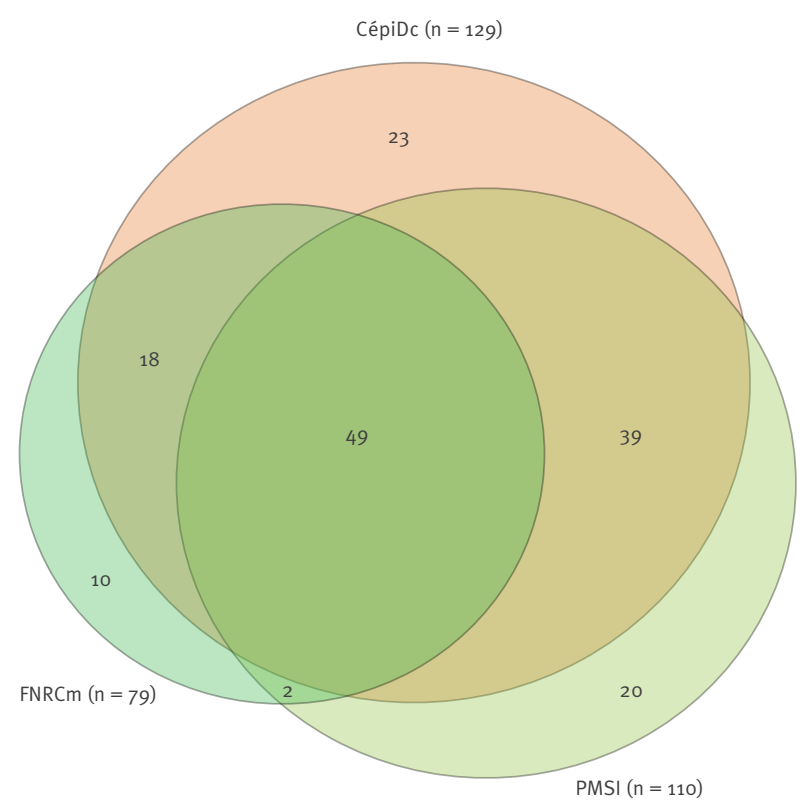

CépiDc: French National Registry on Medical Causes of Death; FNRCm: French National Reference Centre for Malaria; PMSI: French National Hospital Discharge Database (Programme de Médicalisation des Systèmes d'Information).

FNRCm is to monitor the morbidity and mortality of imported malaria, investigate autochthonous cases and assess the chemosensitivity of $P$. falciparum isolates. It provides health authorities with real-time information on malaria-specific events, such as increasing cases from particular transmission areas, emergence of resistance to available drugs or re-emergence of malaria in French non-endemic areas or territories [1820]. Clinical and epidemiological data are collected for each individual diagnosed with malaria.

\section{Case definitions}

Malaria-related death was defined as a death occurring in an acute infectious context with the presence of malaria severity criteria combined with the absence of another cause likely to be life-threatening in the short term. Severe malaria cases were defined using the 2007 revision of the 1999 consensus conference $[21,22]$.

\section{Study population strategy}

To carry out this work, the first step was to merge the databases from two sources that aim at exhaustive collection of deaths and their causes (CépiDC and PMSI) and from a source with a partial and targeted collection (FNRCm) and remove any duplicates. As the CépiDC and PMSI databases were not independent (Supplementary Table S1), a merger was carried out between them (CépiDC-PMSI). Owing to the great heterogeneity in the collection and coding of the causes of death in the CépiDC and PMSI databases, our second concern was to rule out deaths potentially linked to a cause other than malaria.

\section{Merging cases}

The merging of the databases was carried out using a unique key derived from sex, the month of death, the year of death and the place of death. For deduplication and validation of cases, we used the variable 'age at death', which was common to all sources of data. When the age difference of matched cases was equal to zero, the merging was validated. Otherwise, couples of paired patients with differences in the age at death (i.e. differences not equal to zero) were manually checked for validation by comparing all available data.

\section{Selection of malaria-related deaths}

Each report from selected patients was carefully checked in parallel by two parasitologists (MT and RP) and one specialist in infectious diseases (SJ) to classify the cases according to the most likely causes of death (malaria but also suicide, trauma, cancer, lymphoma, knife or firearm wound, stroke, etc). To accomplish this first step, the experts met to rule on the discordant cases. If the three experts did not agree that malaria was the most likely cause of death, the case was excluded.

\section{Statistical analysis}

Capture-recapture methods

These methods are used to estimate the size of a population when a census may be infeasible or impossible to conduct. A portion of the population is captured, marked and released. Later, another portion will be captured and the number of marked individuals within the sample is counted.

Dependence between sources was assessed through two-by-two contingency table analysis and odds ratios with $95 \%$ confidence intervals $(\mathrm{CI})[23,24]$.

Sensitivity analysis: log-linear models [25]

To validate our methodology, log-linear models incorporating interaction terms to account for dependencies between the three overlapping sources were used to predict the number of unobserved deaths and, hence, the total number of deaths in the study population. The significance of each interaction was assessed using likelihood ratio statistics, and goodness of fit of the model was measured by the deviance. The Akaike information criterion (AIC) and Bayesian information criterion (BIC) were used for the model selection.

Stratification was made for sex, age at death (coded as $<50$ years-old and $\geq 50$ years-old), and place of death to take into account the heterogeneity between the data sources. The place of death was categorised as Paris region vs other regions since Paris represented $37 \%(49 / 132)$ of hospitals participating in the FNRCm network during the study period. 
Log-linear-based estimates of the number of individual deaths from Plasmodium malaria according to the physician experts' classification, metropolitan France, 2005-2014 ( $\mathrm{n}=161)$

\begin{tabular}{|c|c|c|c|c|c|c|c|c|}
\hline Model & DoF & $\mathrm{G}^{2}$ & $\mathrm{p}$ & AIC & $\mathrm{BIC}$ & $\begin{array}{l}\text { Unknown } \\
\text { deaths }\end{array}$ & n estimated & $95 \% \mathrm{Cl}$ \\
\hline Main effects onlya (CépiDc, PMSI, FNRCm) & 3 & 20.58 & $<0.00$ & 14.58 & 14.74 & 7 & 168 & $163-176$ \\
\hline Main effects + (CépiDc $\left.{ }^{a}-P M S I\right)$ & 4 & 17.72 & $<0.00$ & 13.72 & 13.83 & 11 & 172 & $164-187$ \\
\hline Main effects +(CépiDc $\left.{ }^{a}-F N R C m\right)$ & 4 & 13.97 & $<0.00$ & 9.97 & 10.08 & 11 & 172 & $165-184$ \\
\hline Main effects + (PMSI $\left.{ }^{a}-\mathrm{FNRCm}\right)$ & 4 & 20.53 & $<0.00$ & 16.53 & 16.64 & 6 & 167 & $162-177$ \\
\hline Main effects + (CépiDc $\left.{ }^{\mathrm{a}}-\mathrm{PMSI}, \mathrm{PMSI}^{\mathrm{a}}-\mathrm{FNRCm}\right)$ & 5 & 17.65 & $<0.00$ & 15.65 & 15.71 & 12 & 173 & $164-194$ \\
\hline Main effects + (CépiDc $\left.{ }^{\mathrm{a}}-\mathrm{FNRCm}, \mathrm{PMSI}^{\mathrm{a}}-\mathrm{FNRCm}\right)$ & 5 & 13.93 & $<0.00$ & 11.93 & 11.99 & 11 & 172 & $164-187$ \\
\hline $\begin{array}{l}\text { Main effects + (CépiDc }{ }^{\mathrm{a}}-\mathrm{PMSI} \text {, CépiDc }{ }^{\mathrm{a}}-\mathrm{FNRCm} \text {, } \\
\text { PMSI }- \text { FNRCm) }\end{array}$ & 6 & 0 & 1 & 0 & 0 & 160 & 321 & $191-1,383$ \\
\hline
\end{tabular}

AIC: Akaike information criterion; BIC: Bayesian information criterion; CépiDc: French National Registry on Medical Causes of Death; CI:

confidence interval; DoF: degree of freedom; FNRCm: French National Reference Centre for Malaria; G2: likelihood ratio G² hypothesis test; PMSI: French National Hospital Discharge Database (Programme de Médicalisation des Systèmes d'Information).

${ }^{\text {a }}$ Main effects only is the model with CépiDc, PMSI and FNRCm, without interaction terms.

Models include interaction terms involved in the adjustment of estimates for dependence among sources.

Estimating the sensitivity of each source using the capture-recapture method

The sensitivity of each source is a measure of how well the source performs in finding cases. The sensitivity was estimated by dividing the number of cases found using the case-finding procedure by the estimate of the total number of cases in the study population found by the capture-recapture method.

Representativeness of the FNRCm network

The representativeness of the FNRCm surveillance system was assessed by comparing the age, sex and administrative region structure of malaria-related deaths with those from CépiDc combined with PMSI over the same period. We assumed that malaria-related deaths selected from these sources were representative of the total malaria-related deaths in France.

Statistical analyses were performed using JMP pro, version 13.1 (SAS Institute). Log-linear models were performed using Stata, version 15.0 (StataCorp., College Station, United States). A difference was considered significant when $p<0.05$. All reported $p$ values were two-tailed.

\section{Ethical statement}

Approval of the study was obtained from the Ethics Committee for Biomedical Research of the French National Agency for Medicines and Health Products (ANSM) in declaration number ID RCB: 2018-A0246946 with a waiver of specific consent by the patients. Permission was sought and granted to access these data on 11 August 2017, by the Ethics Committee of the French Institute for Public Health Surveillance (SPF). Data collection and storage by the FNRCm were approved by the French National Commission for Data Protection and Liberties (CNIL) under declaration number 1223103 . All data from the FNRCm sources were deidentified by removing names and scrambling all other personal identifiers.

\section{Results}

From 2005 to 2014 , the experts reclassified 151 deaths from CépiDc and PMSI as associated with malaria, of which 129 were registered in CépiDc and 110 in PMSI (Figure 1). For the same period, 79 deaths were selected from the FNRCm, of which 69 overlapped with both CépiDc and PMSI (Figure 2). After removing duplicate cases, the overall number of malaria-related deaths resulting from the combination of both data sources was 161.

\section{Interdependence between CépiDc-PMSI and FNRCm}

Prior analysis had shown a dependence between Cépidc and PMSI (Supplementary Table S1); however, the two-by-two contingency table analysis suggested independence between the combined CépiDc-PMSI and FNRCm, with OR $=0.72$ (95\% Cl: 0.38-1.37).

\section{Two-by-two capture-recapture models (CépiDc-PMSI vs FNRCm)}

Using the two-by-two capture-recapture method without taking into account heterogeneity factors, the FNRCm malaria-related deaths surveillance had a $46 \%$ (95\% Cl: 44-54) sensitivity, leading to an estimated number of in-hospital malaria-related deaths in metropolitan France of 172 (95\% Cl: 165-184), of which 11 (95\% Cl: 8-15) were not captured by either source (Supplementary Figure S1).

\section{Sensitivity analysis: Log-linear models}

Estimates based on the log-linear models are shown in Table 1. The final model with the smallest AIC values, corresponding to a better adapted model, was the one with interaction between CépiDc and FNRCm, leading to 172 (95\% Cl: 165-184) estimated deaths.

This number was similar to the previous estimation made by the two-by-two capture-recapture method (Supplementary Figure S1). However, when accounting for age as a heterogeneity factor, the overall estimated 
Estimates of the total number of malaria-related deaths stratified by sex, age in years and place of death, metropolitan France, 2005-2014 ( $=161)$

\begin{tabular}{|c|c|c|c|c|c|c|c|c|c|}
\hline & CépiDc-PMSI & $\mathrm{FNRCm}$ & $\begin{array}{c}\text { (CépiDc- } \\
\text { PMSI) + FNRCm }\end{array}$ & $\begin{array}{l}\text { FNRCm } \\
\text { alone }\end{array}$ & $\begin{array}{l}\text { CépiDc-PMSI } \\
\text { alone }\end{array}$ & $\operatorname{Var}(\mathrm{n})$ & $X ?$ & n estimated & $95 \% \mathrm{Cl}$ \\
\hline \multicolumn{10}{|l|}{ Sex } \\
\hline Female & 41 & 27 & 23 & 4 & 18 & 6.551 & 3 & 48 & $43-53$ \\
\hline Male & 110 & 52 & 46 & 6 & 64 & 22.566 & 8 & 124 & $115-134$ \\
\hline \multicolumn{10}{|l|}{ Place of death } \\
\hline Paris region & 60 & 28 & 25 & 3 & 35 & 11.29 & 4 & 67 & $61-74$ \\
\hline Other regions & 91 & 51 & 44 & 7 & 47 & 17.925 & 7 & 105 & $97-114$ \\
\hline \multicolumn{10}{|l|}{ Age (years) } \\
\hline$<50$ & 48 & 30 & 24 & 6 & 24 & 13.46 & 11 & 65 & $58-72$ \\
\hline$\geq 50$ & 103 & 49 & 45 & 4 & 58 & 12.849 & 33 & 140 & $133-147$ \\
\hline
\end{tabular}

CépiDc: French National Registry on Medical Causes of Death; Cl: confidence interval; FNRCm: French National Reference Centre for Malaria; X?: unknown number of deaths; PMSI: French National Hospital Discharge Database (Programme de Médicalisation des Systèmes d'Information); $\operatorname{Var}(\mathrm{n})$ : variance.

number of individual malaria-related deaths was substantially higher, 205 (95\% Cl: 191-219), consequently reducing the sensitivity of the $\mathrm{FNRCm}$ network to $38 \%$ (95\% Cl: $32 \%-44 \%$ ). This number was particularly high for the age group $\geq 50$ years with 140 deaths (95\% $\mathrm{Cl}$ : 133-147). In contrast, the variables sex and place of death were not found to be heterogeneity factors in this study (Table 2). Given these results, the mean annual estimated number of deaths caused by malaria in France was 21 (95\% Cl: 19-22).

\section{General characteristics of the 161 deaths} captured by the PMSI, CépiDc and FNRCm The malaria-related deaths collected by the PMSI, CépiDc and FNRCm accounted for 78.5\% (95\% Cl: $72.4-$ 83.6) of the estimated number of deaths caused by malaria in metropolitan France from 2005 to 2014. The sex ratio (male to female) was 2.6. The median age of the patients was 57 years (interquartile range: 44-64), ranging from 1 to 89 years. The île-de-France region reported $41.6 \%(n=67)$ of the deaths (Supplementary Table S2).

\section{Representativeness of the FNRCm network}

Compared with the three sources combined (CépiDcPMSI-FNRCm), the proportion of individual malariarelated deaths was smaller in the $\mathrm{FNRCm}$ for the age group $\geq 50$ years $(62.0 \%$ vs $66.5 \%)$ and for men $(65.8 \%$ vs $72.1 \%$ ), but the differences were not statistically significant. The geographical distribution of the number of deaths caused by malaria was significantly different between the FNRCm and the three sources combined. Malaria-related deaths reported to FNRCm were mostly from the regions Pays de la Loire, Provence-Alpes-Côte d'Azur and Nouvelle Aquitaine (Supplementary Table S3).

\section{Discussion}

This study was the first attempt to estimate the total number of deaths caused by malaria in metropolitan
France. From 2005 to 2014, the total number of malaria-related deaths in hospitals estimated by capture-recapture methods was 205 (95\% Cl: 191-219), which was notably different from the 79 deaths reported to the FNRCm. Consequently, only 38\% (95\% $\mathrm{Cl}: 32-44)$ of malaria-related deaths were reported to the FNRCm, leading to an overall estimate of 21 (95\% $\mathrm{Cl}:$ 19-22) deaths per year. Given the completeness of our surveillance system, which captures between 50\% and $53 \%$ of cases, our finding was surprising $[9,11]$. The FNRCm surveillance system is less sensitive in the capture of deaths than the capture of cases. This discrepancy suggests that deaths occur more frequently in hospitals not included in the FNRCm network. However, because information on population structure is lacking, we are not able to conclude on differences in the population structure of people with malaria reported to the $F N R C m$ by the network of participating hospitals (mainly teaching hospitals or inter-regional/ departmental hospitals in large cities) and other hospitals that see fewer cases of malaria infection.

The strengths of this study include the ability of our surveillance system to estimate the number of deaths from malaria and the stability in the morbidity and mortality trend previously established by the FNRCm network over time [2]. Comparison of malaria morbidity and mortality data within and between countries using standard indicators weighted according to the estimated completeness of health surveillance systems is imperative to allow reliable evaluation of malaria surveillance programmes and to homogenise disease surveillance policies in all EU countries. In the UK and the Netherlands, where malaria is a notifiable disease, the case reporting systems have $56 \%$ and $40.2 \%$ sensitivity, respectively. However, this statistic is not available for malaria deaths $[7,26]$. Consequently, there could be a substantial difference between the collection of cases and deaths, as reported in our study. In contrast to the high completeness of malaria cases reported in France, the sensitivity of the system in Portugal 
was higher for malaria deaths $(26.5 \%)$ than for cases $(21.2 \%)[6]$.

Once the data were analysed for age, sex and place of death of the deceased, there were more estimated malaria deaths among people aged 50 years and older than in those younger than 50 years: 140 deaths (95\% $\mathrm{Cl}: 133-147)$ vs 65 deaths ( $95 \% \mathrm{Cl}: 58-72$ ). A study conducted in intensive care units in France has shown that a 10 -year increase in age was associated with a $72 \%$ increase in the odds of hospital death [27]. Similarly, other studies on reported malaria deaths demonstrated that age was a risk factor for predicting death in patients [28-32].

Our study highlights a marked difference between male and female patients who died of malaria in metropolitan France (sex ratio: 2.6). This seems surprising since evidence in the literature suggests that, given equal exposure and apart from the specific case of pregnancy, adult men and women are equally vulnerable to malaria infection with no differences regarding specific mortality in malaria endemic areas [33,34]. However, similar findings have already been reported in the literature regarding reported malaria in high-income countries (sex ratio: $1.5-5.0$ ) [27,28,32,35,36]. Differences between the sexes in the incidence and severity of infection may be related to genetic and physiological constitutions [37] or to differences in exposures or immunity [38]. Although a causal relationship has not been established, many elements confirm this sex difference. For instance, studies have shown that female sex is independently associated with receiving pretravel health information and with increased concern about travel stressors $[39,40]$. Based on data from 58,908 patients in the GeoSentinel networks, Schlagenhauf et al. reported that women were significantly more likely to have sought pretravel advice (odds ratio $(O R)=1.28$; $95 \% \mathrm{Cl}: 1.23-1.32)$, were proportionately less likely to have febrile illnesses ( $\mathrm{OR}=0.15 ; 95 \% \mathrm{Cl}$ : 0.10-0.21) or vector-borne diseases (such as malaria) $(O R=0.46$; 95\% Cl: $0.41-0.51)$ and were less likely to be hospitalised $(\mathrm{OR}=0.45 ; 95 \% \mathrm{Cl}: 0.42-0.49)$ [38]. A difference in the behaviour of men and women with respect to malaria prevention or care is suspected, but the role of a genetic difference is not formally excluded. The lack of difference between the sexes observed in endemic areas could be explained by the protective effect of immunity in adults [41]. Therefore, there is a real need for future travel medicine research to address sex-specific intervention strategies and differential susceptibility to malaria.

Our study also showed that the estimated number of malaria-related deaths reported from the Paris region represented $38 \%$ of the total malaria-related deaths (Table 2). This can be explained by the fact that most cases were diagnosed in the île-de-France region $(n=25,647 ; 56.6 \%)$, the French administrative region surrounding Paris, with 12,082,144 inhabitants in
January 2015 and $37 \%$ of hospitals participating in the FNRCm network.

\section{Limitations}

The first limitation concerns the accuracy of data from CépiDc and PMSI. Clinical information for some patients was not sufficient to conclude whether the death was caused by the malaria. Indeed, in the capture-recapture method, inclusion of cases with an erroneous diagnosis leads to underestimation of the real number of cases (because false positive cases cannot be recaptured). Consequently, if the experts had been less strict on the definition of malaria-related deaths, the inclusion of non-malaria deaths would have resulted in an underestimation of the completeness of the sources and therefore, the estimation of individual malaria-related deaths. Conversely, not including all the true cases in the first capture step does not induce estimation bias since the final result is related to the proportion of recaptured cases and not to the absolute number of recaptured cases. Indeed, according to fundamental assumptions of capture-recapture methods, i.e. independence of the sources and equal probability of individual cases being captured within any source regardless of the number of deaths selected, each death from the CépiDc-PMSI had the same probability of being recaptured by the FNRCm. Reducing the estimated number of malaria deaths selected should therefore not affect the estimates of completeness of the data sources and, consequently, the estimation of the number of deaths caused by malaria. Owing to the delays in making data available from the national databases of CépiDc and the PMSI, our study covered data until the end 2014. However, since 2014, the network of FNRCm correspondents has remained stable, and even though the first-line drug for the treatment of severe malaria changed in 2011 (artesunate replaced quinine), there was no significant impact on mortality, which was already very low in our hospital network [42]. Moreover, in view of the FNRCm data on deaths and CFR during the period 2015 to 2018, there was no significant variation in the CFR compared with the period 2005 to 2014 (Supplementary Table S4). Another limitation of this study is that it exclusively concerned patients who died in the hospital. Patients who died at home were not included in either the PMSI or FNRCm, making an estimate of this number not feasible by this method. However, the CépiDC can indicate an order of magnitude for this number since, in the study period, 29 deaths that occurred outside the hospital were declared (ca three per year). A range close to reality should therefore be between four and five additional deaths per year.

\section{Conclusion}

The pertinent finding in this report is the significant difference in the completeness of malaria-related deaths compared with cases. Therefore, data comparison of malaria morbidity and mortality between countries, especially in TESSy, should be assessed by using standard indicators weighted according to the 
completeness of countries' health surveillance systems for malaria cases and deaths. It is also appropriate, in the FNRCm, to improve the exhaustiveness of the collection of malaria-related deaths that frequently occur outside our network. One of the approaches to improve this exhaustiveness might be to involve further laboratories/hospitals in smaller cities that carry out the diagnosis of malaria. The current modifications made to the structure of the FNRCm network should be validated and routinely combined to improve the completeness of malaria death reporting and information used to conduct timely preventive measures by public health authorities.

\section{*Authors' correction}

At publication, the Abstract stated that malaria-related death records were "more complete" than case records, while it should have read "less complete". This error was corrected on request of the authors on 24 September 2020.

\section{Acknowledgements}

\section{The French imported malaria Study group:}

C. Strady (CHU Reims), Caroline Lohmann ( $\mathrm{CH}$ du Moenchsberg, Mulhouse), Celine Arriuberge (CH Trousseau, Paris), Emmanuel Grimprel (CH Trousseau, Paris), Jean-Marie Delarbre (CH du Moenchsberg, Mulhouse), Michel Thibault (CH René Dubos, Pontoise), Mohamadou Niang (CHR Orléans), A. Barrans (CH Sète), A. Martin (CH Périgueux), A. Spiegel (DESP Nord), A. Valentin (CHU Toulouse), A.S. Le Guern (Institut Pasteur, Paris), Adela Angoulvant (CHU KremlinBicêtre, Paris), Adeline Dubois ( $\mathrm{CH}$ Alès), Adrien Genin ( $\mathrm{CH}$ Pays d'Aix), Agathe Lebuisson (CHU Cochin), Agnes Riche ( $\mathrm{CH}$ Angoulême), Agnès Durand (Institut Pasteur, Paris), Agnès Fromont ( $\mathrm{CH}$ Auxerre), Ahmed Aboubacar (CHU de Strasbourg), Ahmed Fateh Ousser (CH Louis Mourier), Aida Taieb (INTS, Paris), Alain Domergue (CH Alès - Cévennes), Alain Gravet ( $\mathrm{CH}$ du Moenchsberg, Mulhouse), Alain Lecoustumier (CH de Cahors), Albert Faye (CHU Robert Debré, Paris), Alexander Pfaff (CHU de Strasbourg), Alexandra Faussart (CHU Bichat-Claude Bernard, Paris), Alexandre Chlilek (CHU Nîmes), Alice Borel (CHU Amiens), Alice Pérignon (CHU Pitié-Salpêtrière, Paris), Ana Mendes-Mreira (CH La Rochelle), André Gardrat (CH d'Evreux), Ange Kissila ( $\mathrm{CH}$ Provins), Angèle $\mathrm{LI}$ ( $\mathrm{CH}$ Creil (Laënnec)), Anne Cady ( $\mathrm{CH}$ Bretagne Atlantique), Anne Debourgogne (CHU de Nancy), Anne Delaval (CHI Robert Ballanger, Aulnay-sous-Bois), Anne Goepp (CHI Villeneuve St Georges), Anne Marfaing-Koka (Hôpital Antoine-Béclère), Anne Pauline Bellanger (CHU Besançon, Jean Minjoz), Anne Vincenot-Blouin (CH Meaux), Anne-Marie Teychene-Coutet (CH Bondy-Jean Verdier), AnneSophie Deleplancque ( $\mathrm{CH}$ Lille), Annick Verhaeghe $(\mathrm{CH}$ de Dunkerque), Annie Motard-Picheloup (CHI Fréjus St Raphaël), Antoine Berry ( $\mathrm{CHU}$ Toulouse), Antoine Huguenin (CHU Reims), Arnaud Bouvet ( $\mathrm{CH}$ Bretagne Atlantique), Audrey Merens (HIA Begin), Aurelie Roide (CHU Lariboisière, Paris), Aurore Sanson (CH Jacques Cœur, Bourges), Aurélie Fricot (CHU Necker), Aurélie Guigon (CHR Orléans), Benfatallah Dhouha (CHU Necker, Paris), Benjamin Wyplosz (CHU Kremlin-Bicêtre, Paris), Benoît Henri (INTS, Paris), Bernadette Buret (CH Niort), Bernadette Cuisenier (CHU Dijon), Bernadette Worms (CHU Dijon), Bernard Faugère (CH Timone, Marseille), Biligui Sylvestre (CHU Pitié-Salpêtrière, Paris), Boualem Sendid (CH Lille), Bruno Megarbane (CHU Lariboisière, Paris), Bruno Pradines (Département Microbiologie et Maladies Infectieuses, Institut de Recherche
Biomédicale des Armées, 13005 Marseille, France, Aix Marseille University, IRD, SSA, AP-HM, VITROME, 13005 Marseille, France, IHU Méditerranée Infection, 13005 Marseille, France, Centre National de Référence du Paludisme, Institut de Recherche Biomédicale des Armées, 13005 Marseille, France), Béatrice Quinet ( $\mathrm{CH}$ Trousseau, Paris), C. Braidy ( $\mathrm{CH}$ du Sud Seine et Marne), C. Farrugia ( $\mathrm{CH}$ de Dourdan), C. Finot (CH de Dreux), Camille Roussel (INTS, Paris), Camille Runel-Belliard (CHU de Bordeaux), Caren Brump (CHU Lariboisière, Paris), Carine Dokoula (CH Jacques Cœur, Bourges), Carmina Camal (CH Louis Mourier), Carole Mackosso (CHU Bichat-Claude Bernard, Paris), Carole Poupon ( $\mathrm{CH}$ de Gonesse), Caroline Garandeau ( $\mathrm{CH}$ Angoulême), Catherine Benoit ( $\mathrm{CH}$ du Sud Seine et Marne), Catherine Branger ( $\mathrm{CH}$ Louis Mourier), Catherine Brehant ( $\mathrm{CH} \mathrm{La}$ Rochelle), Catherine Desideri-Vaillant (HIA Clermont Tonnerre, Brest), Catherine Kauffmann Lacroix (CH Poitiers), Catherine Lafaurie ( $\mathrm{CH}$ d'Epernay), Cecile Hombrouck-Alet (CH Blois), Cecile Ramade (Lyon-Croix-Rousse), Celine Damiani (CHU Amiens), Celine Gourmel (CHU Lariboisière, Paris), Chantal Duhamel (CHU Côte de Nacre), Chantal Garabedian (CH Pays d'Aix), Chralotte Chambrion (INTS, Paris), Christelle Morelle (CHU Montpellier), Christelle Pomares Estran ( $\mathrm{CH}$ Universitaire de Nice), Christelle Prince ( $\mathrm{CH}$ de Cayenne Andrée Rosemon), Christian Durand ( $\mathrm{CH}$ Provins), Christian Fulleda (CHU Lariboisière, Paris), Christian Raccurt (CHU Amiens), Christine Chaigneau (GHPSO, Creil), Christine Chemla (CHRU de Reims), Christine Van batten ( $\mathrm{CH}$ Laënnec, Creil), Christophe Martinaud (HIA Percy, Clamart), Christophe Rapp (HIA Begin), Claire Augé (CHU Bichat-Claude Bernard, Paris), Claire Malbrunot ( $\mathrm{CH}$ Corbeil Essonne), Claudine Febvre ( $\mathrm{CH}$ de Montbéliard), Claudine Sarfati (Hôpital Saint-Louis, Paris), Coralie l'Ollivier ( $\mathrm{CH}$ de la Timone, Marseille), Corinne Huet (Hôpital Louis-Pasteur, Cherbourg-Octeville), Cournac Jean-Marie (HIA Percy, Clamart), Cynthia Pianetti (CH Gabriel Martin, La Réunion), Cécile Angebault (CHU Necker, Paris), Cécile Ficko (HIA Begin), Cécile Garnaud (CHU de Grenoble), Cécile Leprince (CHI Robert Ballanger, Aulnay-sous-Bois), Céliat Merat (CHU Nantes), Céline Dard (CHU de Grenoble), Céline Nourrisson (CHRU Clermont-Ferrand), Céline Tournus (Hôpital Delafontaine, Saint-Denis), Daniel Azjenberg (CHU Dupuytren, Limoges), Daniel Camus (CH Lille), Daniel Lusina (CHI Robert Ballanger, Aulnay-sous-Bois), Daniel Parzy (IMTSSA, Marseille), Denis Pons (CHRU Clermont-Ferrand), Denis Filisetti (CHU Strasbourg), Denis Malvy (CHU de Bordeaux), Didier Basset (CHU Montpellier), Didier Jan $(\mathrm{CH}$ Laval), Didier Poisson (CHR Orléans), Didier Raffenot $(\mathrm{CH}$ Chambéry), Dieudonné Bemba ( $\mathrm{CH}$ Bondy-Jean Verdier), Dominique Maubon (CHU de Grenoble), Dominique Mazier (CHU Pitié-Salpêtrière, Paris), Dominique Popjora $(\mathrm{CH}$ Trousseau, Paris), Dominique Toubas (CHRU de Reims), Dorothée Quino (CHRU Morvan, Brest), Alioune Ndour (INTS, Paris), Ducout Louis (CH de la Côte Basque), Duong Thanh Hai (CHRU Bretonneau), E. Boyer (CH Le Mans), Edgar Ombandza ( $\mathrm{CH}$ Provins), Edith Mazars ( $\mathrm{CH}$ de Valenciennes), Elisabeth Buffet (CH de Epernay), Elodie Collin (CHI Robert Ballanger, Aulnay-sous-Bois), Elodie Meynet (CH Annecy Genevois), Emeline Scherer (CHU Besançon, Jean Minjoz), Emilie Fréalle (CH Lille), Emilie Klein (CHU Lariboisière, Paris), Emilie Sitterle (CHU Necker, Paris), Emily Ronez (CHU Lariboisière, Paris), Emmanuel Dutoit ( $\mathrm{CH}$ Lille), Enrique Casalino (CHU Bichat-Claude Bernard, Paris), Eric Caumes (CHU Pitié-Salpêtrière, Paris), Eric Dannaoui (Hôpital Européen Georges Pompidou, Paris), Eric Gardien ( $\mathrm{CH}$ de Draguignan, Bordeaux), Eric Kendjo (CHU Pitié-Salpêtrière, Paris),Eric d'Ortenzio (CHU Bichat-Claude Bernard, Paris), Ermanno Candolfi (CHU de Strasbourg), Estelle PerraudCateau (CH Poitiers), Eterne Twizeyimana ( $\mathrm{CH}$ du Cotentin), F. Roblot (CH Poitiers), Fabienne Pateyron (CH Provins), Fabrice Bruneel ( $\mathrm{CH}$ de Versailles, André Mignot), Fabrice Legros (CNR du paludisme), Fabrice Simon (HIA Laveran), Fakhri Jeddi (CHU Nantes), Farida M. Benaoudia (CH Troyes), Faïzi Ajana ( $\mathrm{CH}$ Tourcoing), Felix Djossou (CH de Cayenne Andrée 
Rosemon), Firouze Banisadr (CHRU de Reims), Florent Morio (CHU Nantes), Francis Derouin (Hôpital Saint-Louis, Paris), Francois Moussel (CH François-Quesnay, Mantes-La-Jolie), Francoise Foulet (CHU Henri Mondor), François Peyron (LyonCroix-Rousse), Françoise Benoit-Vical (CHU Toulouse), Françoise Botterel (CHU Henri Mondor), Françoise Gayandrieu (CHU Nantes), Françoise Schmitt ( $\mathrm{CH}$ du Moenchsberg, Mulhouse), Frederic Ariey (CHU Cochin, Paris), Frédéric Grenouillet (CHU Jean Minjoz, Besançon), Frédéric Sorge (CHU Necker), Frédérique Gay (CHU Pitié-Salpêtrière, Paris), Frédérique Foudrinier (CHRU de Reims), G. Courrouble ( $\mathrm{CH}$ Blois), G. Gallou (CH de Falaise), G. Julienne (CH Belfort), G. Philippon (Centre Médical CMETE, Paris), Gauthier Pean-dePonfilly (CHU Lariboisière, Paris), Geneviève Grise (CH d'Elbeuf), Ghania Belkacem Belkadi (CH Tenon), Gilbert Lorre (CHD La Roche-sur-Yon), Gilles Gargala (CHU Rouen), Gilles Nevez (CHRU Morvan, Brest), Gisele Dewulf (CH de Valenciennes), Guillaume Désoubeaux (CHRU Bretonneau, Tours), Guillaume Escriou (CHU Bichat-Claude Bernard, Paris), Guillaume Le Loup ( $\mathrm{CH}$ Tenon, Paris), Guillaume Menard (HIA Saint-Anne, Toulon), Guy Carroger (CH Jacques Cœur, Bourges), Guy Galeazzi (CH Louis Mourier), Gwénaël le Moal (CH Poitiers), Hana Talabani (CHU Cochin, Paris), Hanene Abid (CHU Necker, Paris), Helene Broutier (CHI Robert Ballanger, Aulnay-sous-Bois), Herve Pelloux (CHU de Grenoble), Houria Ichou ( $\mathrm{CH}$ Louis Mourier), Hugo Laurent (CHU Lariboisière, Paris), Hélène Broutier (CH Meaux), Hélène Lapillonne ( $\mathrm{CH}$ Trousseau, Paris), Hélène Yera (CHU Cochin, Paris), Hélène savini (HIA Laveran), I. Hermes (CH SaintMalo), Ilhame Tantaoui (CHU Pitié-Salpêtrière, Paris), Isabelle Poilane (CH Bondy-Jean Verdier), Isabelle Amouroux (Hôpital Antoine-Béclère), Isabelle Mazurier (Hôpitaux Civils de Colmar), Isabelle Salimbeni (CH de Cannes), Isabelle Tawa (Centre Médical CMETE, Paris), J Cuziat (CH Saint-Nazaire), J. Bernard Poux ( $\mathrm{CH}$ de Val d'Ariège - Foix), J. Heurtet $(\mathrm{CH}$ Beauvais), J. Rome (CH de Fougères), J. Truchot (CHU Lariboisière, Paris), J.M. Segalin (CHR Orleans), Jacques Gaillat (CH Annecy Genevois), Jacques Le bras (CHU BichatClaude Bernard, Paris), Jacques Thevenot (Centre Médical CMETE, Paris), Jacques Vaucel (CH Saint-Brieuc), Jean Dunand (Hôpital Ambroise Paré), Jean Benjamin Murat $(\mathrm{CH}$ de Roanne), Jean Marie Trapateau (CH Angoulême), Jean Yves Peltier (CHI Poissy-st-germain), Jean-Etienne Pilo (HIA Begin), Jean-Francois Magnaval (CHU Toulouse), Jean-François Faucher (CHU Jean Minjoz, Limoge), Jean-Paul Boutin (DESP Sud), Jean-Paul Couaillac ( $\mathrm{CH}$ de Cahors), Jean-Philippe Breux ( $\mathrm{CH}$ Cholet), Jean-Pierre Hurst ( $\mathrm{CH}$ Jacques Monod, Le Havre), Jean-Yves Siriez (CHU Robert Debré, Paris), Jeanphilippe Bouchara (CHU Angers), Jerome Clain (CHU BichatClaude Bernard, Paris), Jerome Naudin (CHU Robert Debré, Paris), Jordan Leroy (CH Lille), Josette Jehan (CH du Cotentin), Joudia Najid (CHU Pitié-Salpêtrière, Paris), Judith Gorlicki (CHU Lariboisière, Paris), Julie Bonhomme (CHU Côte de Nacre), Julie Brunet (CHU de Strasbourg), Jérome Guinard (CHR Orleans), Karima Cheikh (CHU Henri Mondor), L. Pougnet (HIA Clermont Tonnerre, Brest), Lauren Pull (CHU Robert Debré, Paris), Laurence Millon (CHU Jean Minjoz, Besançon), Laurence Campergue-Mayer (CH Avignon), Laurence Estepa (CH Blois), Laurence Lachaud (CHU Nîmes), Laurent Aaron (CH Jacques Cœur, Bourges), Laurent Bret (CHR Orléans), Laurent Guillaume (CH Blois), Liliane Ciceron (CHU Pitié-Salpêtrière, Paris), Lionnel Bertaux (CNR du paludisme), Lise Musset (Institut Pasteur, Guyane), Louise Basmacyan (CHU Dijon), Loïc Favennec (CHU Rouen), Luce Landraud (CH Louis Mourier), Lucile Cadot (CH Alès Cévennes), Ludovic de Gentile (CHU Angers), Luis Macias (CHU Bichat-Claude Bernard, Paris), Luu-ly Pham (CHU Kremlin-Bicêtre, Paris), M. Cambon (CHRU Clermont-Ferrand), M.F. Biava (CHU de Nancy), M.H. Kiefer (CH du Moenchsberg), M.P. Carlotti (CNR du paludisme), Madeleine Fontrouge ( $\mathrm{CH}$ de Gonesse), Marc Pihet (CHU Angers), Marc Thellier (CHU Pitié-Salpêtrière, Paris), Marie-Catherine Receveur (CHU de Bordeaux), Marie-Claire Machouart (CHU de Nancy), MarieElisabeth Bougnoux (CHU Necker, Paris), Marie-Laure Bigel
(CH François-Quesnay, Mantes-la-Jolie), Marie-Laure Darde (CHU Dupuyrien, Limoges), Marie-Nadège Bachelier ( $\mathrm{CH}$ Jacques Cœur, Bourges), Marion Almeras ( $\mathrm{CH}$ Béziers), Marion Leterrier (CHU Nantes), Marion Leterrier (CHD La Roche-sur-Yon), Martin Danis (CHU Pitié-Salpêtrière, Paris), Martin G (CH du Cotentin), Martine Bloch (CH Louis Mourier), Martine Liance (CHU Henri Mondor, Paris), Marylin Madamet (IMTSSA, Marseille), Matthieu Revest (CHU Pontchaillou, Rennes), Matthieu Mechain (CHU de Bordeaux), Maxime Thouvenin ( $\mathrm{CH}$ Troyes), Mermond Sylvain (Institut Pasteur, Nouméa), Michel Develoux (CH Tenon, Paris), Michel Miegeville (CHU Nantes), Milène Sasso (CHU Nîmes), Mohamed Diaby (CH Vernon), Monique Marty ( $\mathrm{CH}$ La Rochelle), Monique Greze (CH Albi), Monique Lemoine (CHU Bichat-Claude Bernard, Paris), Mouri Oussama (CHU PitiéSalpêtrière, Paris), Muriel Cornet (Hôpital Hôtel-Dieu, Paris), Muriel Mimoun Ayache (CH Trousseau), Muriel Nicolas (CHU Pointe-à-Pitre / Abymes), Muriel Roumier (CH Arles), Muriel Silva ( $\mathrm{CH}$ Jacques Monod), Mylène Penot (CERBA), Myriam Gharbi (CHU Bichat-Claude Bernard, Paris), Nadia Guennouni (CHU Bichat-Claude Bernard, Paris), Nadine Godineau (Hôpital Delafontaine, Saint-Denis), Naima Dahane (CHU Cochin, Paris), Nathalie Bourgeois (CHU Montpellier), Nathalie Desuremain (CH Trousseau, Paris), Nathalie Fauchet (CHI de Créteil), Nathalie Parez (CH Louis Mourier), Nathalie Wilhelm (CH de Cahors), Nawel Ait-Ammar (Hôpital Ambroise Paré), Nayla Nassar (CH Auxerre), Nicolas Argy (CHU BichatClaude Bernard, Paris), Nicolas Blondiaux (CH Tourcoing), Nicolas Taudon (CERBA), Nicole Desbois-Nogard (CHU de la Martinique), Noura Hassouni (CHU Necker), Odile BouretDubouis ( $\mathrm{CH}$ Bretagne Atlantique), Odile Eloy ( $\mathrm{CH}$ de Versailles, André Mignot), Odile Falguiere (CH Béziers), Odile Fenneteau (CHU Robert Debré, Paris), Olivia Bandin (Hôpital Saint-Camille/Bry-sur-Marne), Olivier Albert (CHU de Bordeaux), Olivier Bouchaud (CH Bobigny-Avicenne), Olivier Patey (CHI Villeneuve St. Georges), Olivier Rogeaux ( $\mathrm{CH}$ Chambéry), P. Clergeau (CH Sallanches), P. Daumain (CH de Dourdan), P.H. Consigny (Institut Pasteur, Paris), Paméla Chauvin (CHU Toulouse), Pascal Delaunay (CH Universitaire de Nice), Pascal Hazera (CH Saint-Lo), Pascal Houze (Hôpital Saint Louis, Paris), Pascal Millet (CHU de Bordeaux), Pascal Pouedras ( $\mathrm{CH}$ Bretagne Atlantique), Pascale Penn (CH Le Mans), Patrice Agnamey (CHU Amiens), Patrice Bourrée (CHU Kremlin-Bicêtre, Paris), Patricia Barbut ( $\mathrm{CH}$ Longjumeau), Patricia Brugel ( $\mathrm{CH}$ Antibes Juan-Les-Pins), Patricia Roux (CH Saint-Antoine, Paris), Patrick Leguen (HIA Clermont Tonnerre, Brest), Patrick Valayer (CH Notre-Dame de la Miséricorde), Pauline Caraux-Paz (CHI Villeneuve St Georges), Pauline Touroultjupin ( $\mathrm{CH}$ Cholet), Philippe Abboud (CHU Rouen), Philippe Cormier (CH d'Evry), Philippe Minodier (CH Marseille Nord), Philippe Moskovtchenko (Hôpitaux Civils de Colmar), Philippe Parola (CH Marseille Nord), Philippe Poirier (CHRU Clermont-Ferrand), Philippe Stolidi (CH Aubagne), Pierre Patoz (CH Tourcoing), Pierre Buffet (INTS, Paris), Pierre Buffet (CHU Pitié-Salpêtrière, Paris), Pierre Flori (CH Saint-Etienne), Pierre Marty (CH Universitaire de Nice), Pierre Mornand ( $\mathrm{CH}$ Trousseau, Paris), Pinel Claudine (CHU de Grenoble), R. Dahan (CHU de Strasbourg), R. Devallière (CH Saint-Nazaire), R. Mazataud (CH Vitry le François), Rahaf Haj Hamid (CH Louis Mourier), Regis Courtin (CHU Pitié-Salpêtrière, Paris), Renaud Blonde (CHU Robert Debré, Paris), René Nabias (CHI Poissy-st-germain), Roland Fabre (HIA Begin), Rose-Anne Lavergne (CHU Nantes), Roxane Courtois (CH Cholet), Rym Chouk Turki (CHU Henri Mondor), Rémy Durand (CH BobignyAvicenne), Réné Nabias (CHU Necker, Paris), Sabah Kubab (CH Corbeil Essonne), Sabine Lasserre (CH Trousseau, Paris), Samia Hamane (Hôpital Saint-Louis, Paris), Sandrine Cojean (CHU Bichat-Claude Bernard, Paris), Sandrine Houze (CHU Bichat-Claude Bernard, Paris), Sophie Matheron (CHU BichatClaude Bernard, Paris), Sorya Belaz (CHU Pontchaillou, Rennes), Stephane Jaureguiberry (CHU Pitié-Salpêtrière, Paris), Stephane Ranque ( $\mathrm{CH}$ de la Timone, Marseille), Stephanie Dulucq (CHU de Bordeaux), Stéphane Bretagne (Hôpital Saint-Louis, Paris), Stéphane Pelleau (Institut 
Pasteur, Guyane), Stéphane Picot (Hospices Civils de Lyon), Sylvain Clauser (Hôpital Ambroise Paré), Sylviane Chevrier (CHU Pontchaillou, Rennes), Sylviane Dydymski (CHRU Clermont-Ferrand), Sylvie Lariven (CHU Bichat-Claude Bernard, Paris), Sylvie Lhopital (CH Vernon), Sylvie Maurellet Evrard (CHI Villeneuve St Georges), Sylvie Roulaud (CH Angouleme), Sébastien Larréché (HIA Begin), Thi-Hai-Chau Trinh (CHR Orléans), Thierry Ancelle (CHU Cochin, Paris), Thierry Pistone (CHU de Bordeaux), Thomas Hanslik (Hôpital Ambroise Paré), Thomas Guimard (CHD La Roche-sur-Yon), Timothée Klopfenstein (CHU Besançon, Jean Minjoz), Valerie Fuster-Dumas (CHU de Bordeaux), Veronique Blanc-Amrane (CH Antibes Juan-Les-Pins), Veronique Delcey (CHU Lariboisière, Paris), Veronique Sarrasin-Hubert (CHU BichatClaude Bernard, Paris), Vincent Foissaud (HIA Percy, Clamart), Virginie Mouton-Rioux (CH Bretagne Atlantique), Virginie Vitrat (CH Annecy Genevois), Véronique Jan-Lasserre (CH Lagny-sur-Marne), Xavier Nicolas (HIA Clermont Tonnerre, Brest), Y. Costa (CH Lagny-sur-Marne), Yassamine Lazrek (Institut Pasteur, Guyane), Yaye Senghor (Hôpital Saint Joseph, Paris), Yohann Le Govic (CHU Angers), Yves Guimard ( $\mathrm{CH}$ Jacques Cœur, Bourges), Yves Poinsignon (CH Bretagne Atlantique), Claude flamand (Institut Pasteur, Guyane), C.N. guyen (CH Trousseau, Paris), G. Noël (CH Marseille Nord), G. Soula ( $\mathrm{CH}$ Marseille Nord), J.M.Didier ( $\mathrm{CH}$ Vesoul), M.F. Raynaud (CH Antibes Juan-Les-Pins), M. Julien (CH Béziers), M. Morillon (HIA Laveran), M.P. Carlotti (IMTSSA), P. Chantelat (CH Vesoul), P. Dussert (CH Belfort), P. Ralaimazava $(\mathrm{CH}$ Bobigny-Avicenne), S. Zaouche (CHU Necker, Paris), Élodie Lesteven (CHU Lariboisière, Paris).

\section{Conflict of interest}

None declared.

\section{Authors' contributions}

Eric Kendjo contributed to conception and design, completed the data analysis and interpretation of data, and drafted and edited the manuscript. Marc Thellier and Renaud Piarroux Obtained funding, supervised and provided many of the condition definitions, contributed to the statistical analysis and interpretation of data, and revised the manuscript critically for important intellectual content. Noël Harold and Alexandra Septfons participated in the conception and design of the study had access to all administrative data from the study (CépiDc and PMSI) and takes responsibility for the integrity of the data. Ilhame Tantaoui collected, completed and controlled the quality of data. Sandrine Houze, Eric Caumes, Oussama Mouri, Frédérick Gay and Stéphane Jauréguiberry revised the manuscript critically for important intellectual content. Stéphane Jauréguiberry, Marc Thellier and Renaud Piarroux participated in the expert group for the selection of malaria deaths in the CépiDC and PMSI databases. All authors read and approved the final manuscript.

\section{References}

1. Ritchie H, Roser M. Causes of death. Oxford: Our World In Data; 2018. Available from: https://ourworldindata.org/ causes-of-death

2. World Health Organization. The top 10 causes of death. Geneva: WHO: 2018. Available from: https://www.who.int/ topics/mortality/en/

3. European Centre for Disease Prevention and Control (ECDC). Malaria. In: Annual epidemiological report for 2017. Stockholm: ECDC; 2019. Available from: https://www.ecdc.europa.eu/ sites/default/files/documents/AER for 2017-malaria.pdf

4. Tatem AJ, Jia P, Ordanovich D, Falkner M, Huang Z, Howes R, et al. The geography of imported malaria to non-endemic countries: a meta-analysis of nationally reported statistics. Lancet Infect Dis. 2017;17(1):98-107. https://doi.org/10.1016/ S1473-3099(16)30326-7 PMID: 27777030
5. Cathcart SJ, Lawrence J, Grant A, Quinn D, Whitty CJ, Jones J, et al. Estimating unreported malaria cases in England: a capturerecapture study. Epidemiol Infect. 2010;138(7):1052-8. https:// doi.org/10.1017/So950268809991130 PMID: 19919729

6. Fonseca AG, Simões Dias S, Baptista JL, Torgal J. Surveillance of imported hospital requiring malaria in Portugal: can it be improved? Eur J Public Health. 2016;26(3):403-6. https://doi. org/10.1093/eurpub/ckw052 PMID: 27069002

7. van Hest NA, Smit F, Verhave JP. Underreporting of malaria incidence in The Netherlands: results from a capture-recapture study. Epidemiol Infect. 2002;129(2):371-7. https://doi. org/10.1017/S0950268802007306 PMID: 12403113

8. Ferrao AR. The possibility of reintroduction of Malaria in Portugal: are surveillance systems doing enough? Int J Infect Dis. 2019;79:147. https://doi.org/10.1016/j.ijid.2018.11.359

9. Kendjo E, Houzé S, Mouri O, Taieb A, Gay F, Jauréguiberry $\mathrm{S}$, et al. Epidemiologic trends in malaria incidence among travelers returning to Metropolitan France, 1996-2016. JAMA Netw Open. 2019;2(4):e191691. https://doi.org/10.1001/ jamanetworkopen.2019.1691 PMID: 30951158

10. Société de Pathologie Infectieuse de Langue Française (SPILF). Prise en charge et prévention du paludisme d'importation, mise à jour 2017 des recommandations pour la pratique clinique 2007. [Management and prevention of imported malaria 2017, update of recommendations for clinical practice 2007]. Paris: SPILF; 2017. French. Available from: https://www. srlf.org/prise-charge-prevention-paludisme-dimportationmise-a-jour-2017-recommandations-pratique-clinique-2007/

11. Legros F, Fromage M, Ancelle T, Burg E, Janot C, Maisonneuve $P$, et al. Enquête nationale de recensement des cas de paludisme d'importation en France métropolitaine pour l'année 1997. [National survey of census of imported malaria cases in metropolitan France for 1997]. Bulletin Epidémiologique Hebdomadaire. 1999;11:41-2. French.

12. Institut national de la statistique et des études économiques (INSEE). France. Definition. Paris: INSEE. [Accessed: 6 May 2019]. French. Available from: https://www.insee.fr/en/ metadonnees/definition/c1696e

13. Centre d'épidémiologie sur les causes médicales de décès (CépiDc). Le CépiDc. [The Center of epidemiology on medical causes of death]. Paris: Institut national de la santé et de la recherche médicale. [Accessed: 6 May 2019]. French. Available from: https://www.cepidc.inserm.fr/qui-sommes-nous/ le-cepidc

14. Agence technique de l'information sur l'hospitalisation. Programme de médicalisation des systèmes d'information (PMSI). [French National Hospital Discharge Database]. Paris: Institut national de la santé et de la recherche médicale. [Accessed: 6 May 2019]. French. Available from: https://www. epmsi.atih.sante.fr/welcomeEpmsi.do/

15. Centre de national de référencedu Paludisme (CNRpalu). Rapport annuel d'activité. Année d'exercice 2017 [Annual activity report of the National Malaria Reference Centre for 2017]. Marseille: CNRpalu; 2018. French. Available from: https://anofel.net/wp-content/uploads/2019/07/ra_cnr_2018_ CNPaludisme.pdf

16. Brämer GR. International statistical classification of diseases and related health problems. Tenth revision. World Health Stat Q. 1988;41(1):32-6. PMID: 3376487

17. World Health Organization (WHO). International statistical classification of diseases and related health problems. 10th Revision. Geneva: WHO; 2019. Available from: https://icd.who. int/browse10/2019/en

18. Gharbi M, Pillai DR, Lau R, Hubert V, Khairnar K, Existe A, et al. Chloroquine-resistant malaria in travelers returning from Haiti after 2010 earthquake. Emerg Infect Dis. 2012;18(8):1346-9. https://doi.org/10.3201/eid1808.111779 PMID: 22840888

19. Santé Publique France (SPF). Centres nationaux de référence pour la lutte contre les maladies transmissibles. [National reference centres for the fight against communicable diseases]. Saint-Maurice: SPF; 2020. French. Available from: https://www.santepubliquefrance.fr/a-propos/nos-principesfondateurs/centres-nationaux-de-reference-pour-la-luttecontre-les-maladies-transmissibles

20. Thellier M, Simard F, Musset L, Cot M, Velut G, Kendjo E, et al. Changes in malaria epidemiology in France and worldwide, 2000-2015. Med Mal Infect. 2020;50(2):99-112. PMID: 31257063

21. Société de Pathologie Infectieuse de Langue Française, Collège des Universitaires de Maladies Infectieuses et Tropicales, Société Française de Médecine des Armées, Société Française de Parasitologie, Société Française de Pédiatrie, Société de Médecine des Voyages, et al. [Management and prevention of imported Plasmodium falciparum malaria (Revision 2007 of the 1999 Consensus Conference). Long text in French]. Med Mal Infect. 2008;38(2):68-117. French. PMID: 18646361 
22. Société de Pathologie Infectieuse de Langue Française, Collège des Universitaires de Maladies Infectieuses et Tropicales, Société Française de Médecine des Armées, Société Française de Parasitologie, Société Française de Pédiatrie, Société de Médecine des Voyages, et al. Recommendations for clinical practice. Management and prevention of imported Plasmodium falciparum malaria. (Revision 2007 of the 1999 Consensus conference). Short text. Med Mal Infect. 2008;38(2):54-67, 3953. PMID: 18646360

23. Hook EB, Regal RR. Capture-recapture methods in epidemiology: methods and limitations. Epidemiol Rev. 1995;17(2):243-64. https://doi.org/10.1093/oxfordjournals. epirev.a036192 PMID: 8654510

24. Wittes JT, Colton T, Sidel VW. Capture-recapture methods for assessing the completeness of case ascertainment when using multiple information sources. J Chronic Dis. 1974;27(1):25-36. https://doi.org/10.1016/0021-9681(74)90005-8 PMID: 4815069

25. Cormack RM. Log-linear models for capture-recapture. Biometrics. 1989;45(2):395-413. https://doi. org/10.2307/2531485

26. Checkley AM, Smith A, Smith V, Blaze M, Bradley D, Chiodini $\mathrm{PL}$, et al. Risk factors for mortality from imported falciparum malaria in the United Kingdom over 20 years: an observational study. BMJ. 2012;344(mar27 3):e2116. https://doi.org/10.1136/ bmj.e2116 PMID: 22454091

27. Bruneel F, Tubach F, Corne P, Megarbane B, Mira JP, Peytel E, et al. Severe imported falciparum malaria: a cohort study in 400 critically ill adults. PLoS One. 2010;5(10):e13236. https://doi. org/10.1371/journal.pone.0013236 PMID: 20949045

28. Legros F, Bouchaud O, Ancelle T, Arnaud A, Cojean S, Le Bras , et al. Risk factors for imported fatal Plasmodium falciparum malaria, France, 1996-2003. Emerg Infect Dis. 2007;13(6):883 8. https://doi.org/10.3201/eid1306.060955 PMID: 17553228

29. Greenberg AE, Lobel HO. Mortality from Plasmodium falciparum malaria in travelers from the United States, 1959 to 1987 . Ann Intern Med. 1990;113(4):326-7. https://doi. org/10.7326/0003-4819-113-4-326 PMID: 2197915

30. Sabatinelli G, Majori G, D’Ancona F, Romi R. Malaria epidemiological trends in Italy. Eur J Epidemiol. 1994;10(4):399-403. https://doi.org/10.1007/BF01719663 PMID: 7843343

31. Sabatinelli G, D’Ancona F, Majori G, Squarcione S. Fatal malaria in Italian travellers. Trans R Soc Trop Med Hyg. 1994;88(3):314. https://doi.org/10.1016/0035-9203(94)90097-3 PMID: 7974674

32. Newman RD, Parise ME, Barber AM, Steketee RW. Malariarelated deaths among U.S. travelers, 1963-2001. Ann Intern Med. 2004;141(7):547-55. https://doi.org/10.7326/0003-4819141-7-200410050-00012 PMID: 15466772

33. Roth GA, Abate D, Abate KH, Abay SM, Abbafati C, Abbasi N, et al. Global, regional, and national age-sex-specific mortality for 282 causes of death in 195 countries and territories, 19802017: a systematic analysis for the Global Burden of Disease Study 2017. Lancet. 2018;392(10159):1736-88. https://doi. org/10.1016/S0140-6736(18)32203-7 PMID: 30496103

34. World Health Organization (WHO). The world health report 2007. A safer future. Global public health security in the 21st century. Geneva: WHO; 2007. Available from: https://www. who.int/whr/2007/whro7_en.pdf

35. Lüthi B, Schlagenhauf P. Risk factors associated with malaria deaths in travellers: a literature review. Travel Med Infect Dis. 2015;13(1):48-6o. https://doi.org/10.1016/j.tmaid.2014.04.014 PMID: 25022610

36. Marks ME, Armstrong M, Suvari MM, Batson S, Whitty CJ, Chiodini PL, et al. Severe imported falciparum malaria among adults requiring intensive care: a retrospective study at the hospital for tropical diseases, London. BMC Infect Dis. 2013;13(1):118. https://doi.org/10.1186/1471-2334-13-118 PMID: 23497139

37. Jansen A, Stark K, Schneider T, Schöneberg I. Sex differences in clinical leptospirosis in Germany: 1997-2005. Clin Infect Dis. 2007;44(9):e69-72. https://doi.org/10.1086/513431 PMID: 17407027

38. Schlagenhauf P, Chen LH, Wilson ME, Freedman DO, Tcheng $D$, Schwartz E, et al. Sex and gender differences in travelassociated disease. Clin Infect Dis. 2010;50(6):826-32. https://doi.org/10.1086/650575 PMID: 20156059

39. Cabada MM, Maldonado F, Quispe W, Serrano E, Mozo K, Gonzales E, et al. Pretravel health advice among international travelers visiting Cuzco, Peru. I Travel Med. 2005;12(2):61-5. https://doi.org/10.2310/7060.2005.12201 PMID: 15996449

40. McIntosh IB, Power KG, Reed JM. Prevalence, intensity, and sex differences in travel related stressors. J Travel Med. 1996;3(2):96-102. https://doi.org/10.1111/j.1708-8305.1996. tboo713.x PMID: 9815432
41. Murray CJ, Ortblad KF, Guinovart C, Lim SS, Wolock TM, Roberts DA, et al. Global, regional, and national incidence and mortality for HIV, tuberculosis, and malaria during 19902013: a systematic analysis for the Global Burden of Disease Study 2013. Lancet. 2014;384(9947):1005-70. https://doi. org/10.1016/S0140-6736(14)60844-8 PMID: 25059949

42. El Ket N, Kendjo E, Thellier M, Assoumou L, Potard V, Taieb A, et al. Propensity score analysis of artesunate versus quinine for severe imported Plasmodium falciparum malaria in France. Clin Infect Dis. 2020;70(2):280-7. https://doi.org/10.1093/cid/ ciz206 PMID: 30874798

\section{License, supplementary material and copyright}

This is an open-access article distributed under the terms of the Creative Commons Attribution (CC BY 4.0) Licence. You may share and adapt the material, but must give appropriate credit to the source, provide a link to the licence and indicate if changes were made.

Any supplementary material referenced in the article can be found in the online version.

This article is copyright of the authors or their affiliated institutions, 2020. 